\title{
Silica nanoparticle surface chemistry: An important trait affecting cellular biocompatibility in two and three dimensional culture systems
}

Hasany, Masoud; Taebnia, Nayere; Yaghmaei, Soheila; Shahbazi, Mohammad-Ali; Mehrali, Mehdi; Dolatshahi-Pirouz, Alireza; Arpanaei, Ayyoob

\section{Published in:}

Colloids and Surfaces B: Biointerfaces

Link to article, DOI:

10.1016/j.colsurfb.2019.110353

Publication date:

2019

Document Version

Peer reviewed version

Link back to DTU Orbit

Citation (APA):

Hasany, M., Taebnia, N., Yaghmaei, S., Shahbazi, M-A., Mehrali, M., Dolatshahi-Pirouz, A., \& Arpanaei, A. (2019). Silica nanoparticle surface chemistry: An important trait affecting cellular biocompatibility in two and three dimensional culture systems. Colloids and Surfaces B: Biointerfaces, 182, [110353].

https://doi.org/10.1016/j.colsurfb.2019.110353

\section{General rights}

Copyright and moral rights for the publications made accessible in the public portal are retained by the authors and/or other copyright owners and it is a condition of accessing publications that users recognise and abide by the legal requirements associated with these rights.

- Users may download and print one copy of any publication from the public portal for the purpose of private study or research.

- You may not further distribute the material or use it for any profit-making activity or commercial gain

- You may freely distribute the URL identifying the publication in the public portal 


\section{Accepted Manuscript}

Title: Silica Nanoparticle Surface Chemistry: An Important Trait Affecting Cellular Biocompatibility in Two and Three Dimensional Culture Systems

Authors: Masoud Hasany, Nayere Taebnia, Soheila Yaghmaei, Mohammad-Ali Shahbazi, Mehdi Mehrali, Alireza

Dolatshahi-Pirouz, Ayyoob Arpanaei

PII:

DOI:

Article Number:

S0927-7765(19)30487-4

https://doi.org/10.1016/j.colsurfb.2019.110353

Reference:

110353

To appear in:

COLSUB 110353

Received date:

\section{Colloids and Surfaces B: Biointerfaces}

Revised date:

8 March 2019

Accepted date:

$$
15 \text { June } 2019
$$

6 July 2019

Please cite this article as: Hasany M, Taebnia N, Yaghmaei S, Shahbazi MAli, Mehrali M, Dolatshahi-Pirouz A, Arpanaei A, Silica Nanoparticle Surface Chemistry: An Important Trait Affecting Cellular Biocompatibility in Two and Three Dimensional Culture Systems, Colloids and Surfaces B: Biointerfaces (2019), https://doi.org/10.1016/j.colsurfb.2019.110353

This is a PDF file of an unedited manuscript that has been accepted for publication. As a service to our customers we are providing this early version of the manuscript. The manuscript will undergo copyediting, typesetting, and review of the resulting proof before it is published in its final form. Please note that during the production process errors may be discovered which could affect the content, and all legal disclaimers that apply to the journal pertain. 


\title{
Silica Nanoparticle Surface Chemistry: An Important Trait Affecting Cellular Biocompatibility in Two and Three Dimensional Culture Systems
}

\author{
Masoud Hasany ${ }^{1,2,3}$, Nayere Taebnia ${ }^{1}$, Soheila Yaghmaei ${ }^{3}$, Mohammad-Ali Shahbazi ${ }^{4,5}$, \\ Mehdi Mehrali ${ }^{1}$, Alireza Dolatshahi-Pirouz ${ }^{1,6^{*}}$, Ayyoob Arpanaei $^{2, *}$ \\ ${ }^{1}$ Technical University of Denmark, DTU Nanotech, Center for Intestinal Absorption and Transport of Biopharmaceuticals, 2800 \\ Kgs, Denmark. \\ ${ }^{2}$ Department of Industrial and Environmental Biotechnology, National Institute of Genetic Engineering and Biotechnology, PO \\ Box: 14965/161, Tehran, Iran. \\ ${ }^{3}$ Department of Chemical and Petroleum Engineering, Sharif University of Technology, Tehran, Iran. \\ ${ }^{4}$ Department of Micro- and Nanotechnology, Technical University of Denmark, Ørsteds Plads, DK-2800 Kgs, Lyngby, Denmark \\ ${ }^{5}$ Department of Pharmaceutical Nanotechnology, School of Pharmacy, Zanjan University of Medical Sciences, 45139- 56184, \\ Zanjan, Iran
}

${ }^{6}$ Department of Regenerative Biomaterials, Radboud University Medical Center, Philips van Leydenlaan 25, Nijmegen 6525 EX, The Netherlands.

*Corresponding Authors: AA, arpanaei@yahoo.com and aa@nigeb.ac.ir; ADP, aldo@dtu.dk

Graphical abstract
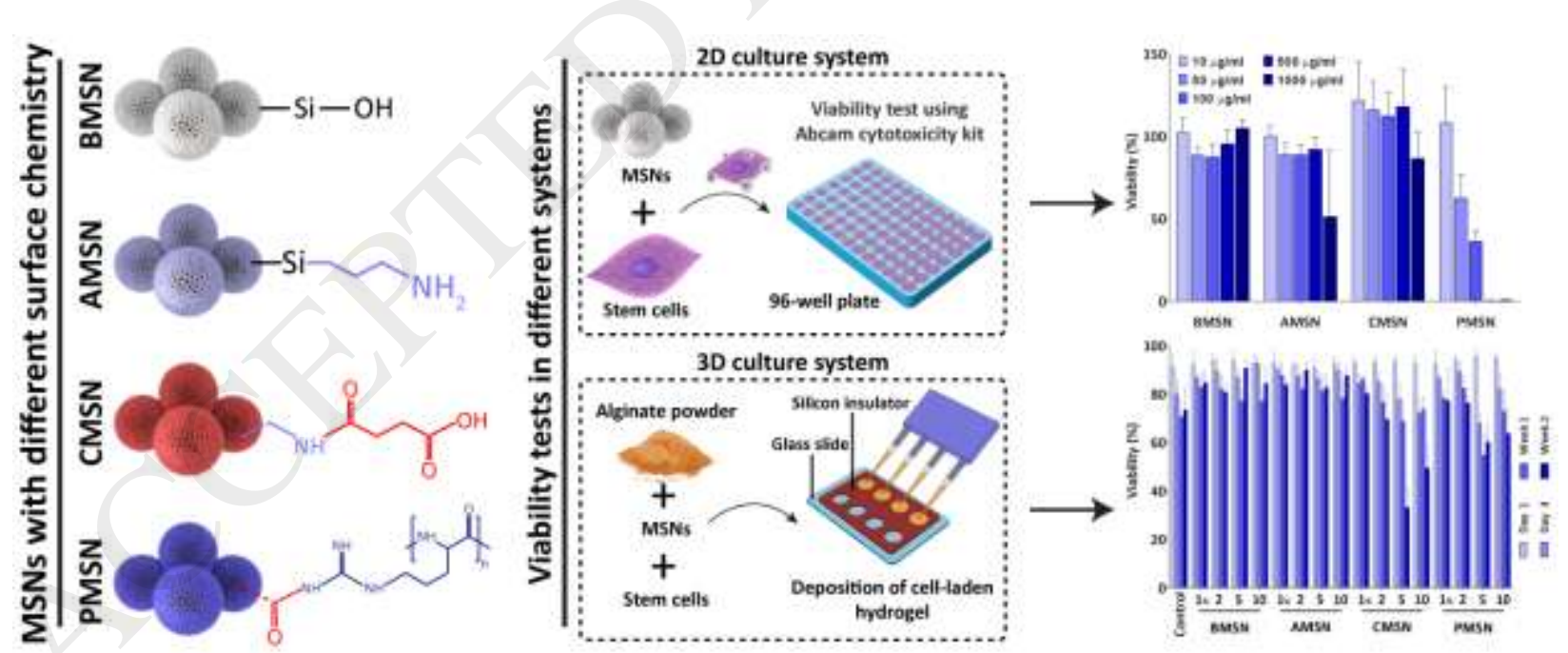

Highlights

- Suitable biocompatibility of both BMSN and AMSN in 2D and 3D hMSCs culture systems

- $\mathrm{CMSN}$ caused higher cell proliferation in the 2D culture system

- CMSN showed cytotoxic effects in the 3D alginate-based culture system 
- PMSN resulted in disrupted morphology and very low viability in the $2 \mathrm{D}$ cell culture

\section{Abstract}

Great advantages bestowed by mesoporous silica nanoparticles (MSNs) including high surface area, tailorable pore diameter and surface chemistry, and large pore volume render them as efficient tools in biomedical applications. Herein, MSNs with different surface chemistries were synthesized and investigated in terms of biocompatibility and their impact on the morphology of bone marrow-derived mesenchymal stem cells both in 2D and 3D culture systems. Bare MSNs (BMSNs) were synthesized by template removing method using tetraethylorthosilicate (TEOS) as a precursor. The as-prepared BMSNs were then used to prepare amine-functionalized (AMSNs), carboxyl-functionalized (CMSNs) and polymeric aminefunctionalized (PMSNs) samples, consecutively. These nanoparticles were characterized by scanning electron microscopy, zeta potential measurement, dynamic light scattering, BET (Brunauer, Emmett, Teller) analysis, and FTIR technique. In a 3D culture system, stem cells were encapsulated in alginate hydrogel in which MSNs of different functionalities were incorporated. The results showed good biocompatibility for both BMSNs and AMSNs in 2D and 3D culture systems. For these samples, the viability of about $80 \%$ was acquired after 2 weeks of 3D culture. When compared to the control, CMSNs caused higher cell proliferation in the 2D culture; while they showed cytotoxic effects in the 3D culture system. Interestingly, polymeric aminefunctionalized silica nanoparticles (PMSNs) resulted in disrupted morphology and very low viability in the $2 \mathrm{D}$ cell culture and even less viability in $3 \mathrm{D}$ environment in comparison to BMSNs and AMSNs. This significant decrease in cell viability was attributed to the striking uptake values of highly positively charged PMSNs by cells that were measured using inductively coupled plasma 
optical emission spectroscopy instrument (ICP-OES). These results uncover different interactions between cell and nanoparticles with various surface chemistries. Building on these results, new windows are opened for employing biocompatible nanoparticles such as BMSNs and AMSNs, even at high concentrations, as potential cargos for carrying required growth and/or differentiation factors for tissue engineering applications.

Key words: Mesoporous silica nanoparticles, human mesenchymal stem cell, poly-Larginine, alginate, cytotoxicity, tissue engineering Highlights:

- Suitable biocompatibility of both BMSNs and AMSNs in 2D and 3D hMSCs culture systems

- $\mathrm{CMSN}$ caused higher cell proliferation in the 2D culture system

- CMSNs showed cytotoxic effects in the 3D alginate-based culture system

- $\mathrm{PMSN}$ resulted in disrupted morphology and very low viability in the 2D cell culture

\section{Introduction}

In the past few decades, nanomaterials have been cemented as promising tools in tissue engineering, drug delivery, and cancer therapy [1-4]. For example, nanomaterials such as graphene, carbon nanotubes, hydroxyapatite particles and nanodiamonds have shown great potential in bestowing superior electrical and mechanical properties to scaffolds required for engineering specific types of tissues [3,5-8]. Indeed, improved electrical conductivity, magnetic properties, and antimicrobial activity are some of the advantages of noble metallic and metal oxide nanostructures such as gold, silver, iron oxide, and titanium nanoparticles; which in turn makes them suitable for biomedical applications [9-11]. Since the discovery of bioactive inorganic materials in animal body, natural and synthetic inorganic nanoparticles have gained a great attention in tissue engineering. A wide range of these nanomaterials including 
nanohydroxyapatite $(\mathrm{nHA})$, silicate, bioactive glasses, and calcium phosphate nanoparticles, have been studied for musculoskeletal tissue engineering applications [12-15].

Among the many different types of inorganic nanomaterials, mesoporous silica nanoparticles (MSNs) hold the greatest promise in biomedical applications. Fig. 1 presents the number of articles published per year with a title containing "mesoporous silica nanoparticle" and the number of citing articles. The steady increase in these numbers indicates a growing interest to MSNs and their applications in different areas. This is certainly due to the attractive properties they present, such as high surface area and pore volume, which ensure sufficient loading and effective release of therapeutic agents [16-19]. Notably, their straightforward synthesis procedure, tunable pore sizes and facile surface functionalization as well as their great biocompatibility have made MSNs excellent candidates in many areas of biomedical applications $[16,18,20]$. As an example, various types of theranostic agents for cancer diagnosis and therapy were developed based on MSNs in recent years [21-24]. MSNs have also been employed to reinforce the mechanical properties of biomaterial scaffolds [25], and to provide biological cues required for directing stem cells toward desired lineages [26-28].

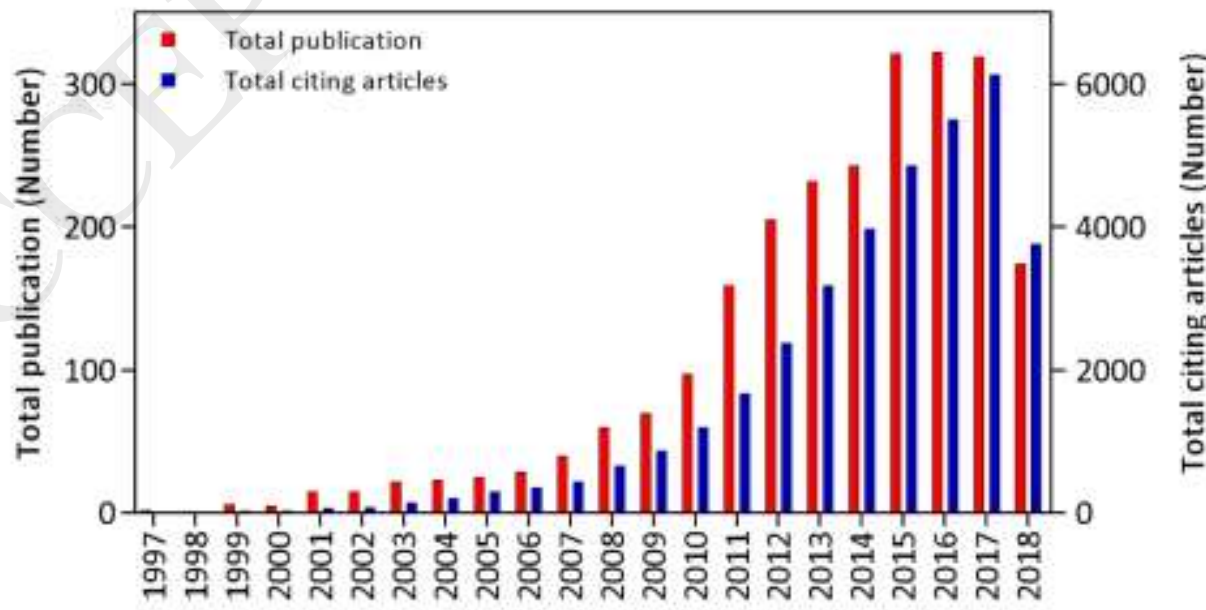

Fig. 1: Number of articles published with a title containing "mesoporous silica nanoparticle" shown in red bars. Number of publications citing the respected articles per year, shown in blue bars. The data were extracted from Web of Science, Clarivate 
Analytics (July 2018).

One of the most important characteristics of biomaterials for tissue engineering is the way they interact with cultured cells. Among the many yet unrecognized interactions, the most basic one is the extent to which a nonnative matter can be applied without cytotoxic effect, namely the material biocompatibility [29]. These interactions between nanomaterials and cells can affect cells morphology, proliferation and fate. It has been shown that the different morphologies in the effect of different culture systems regulate hMSCs fate to either adipocyte or osteoblast cells [30]. On the other hand, the cells morphology can affect the nanoparticles uptake rate and consequently the degree of their cytotoxicity [31]. Farvadi et al. indicated that the cell uptake and cytotoxicity of gold nanorods with an average size of $33.5 \pm 5.5 \mathrm{~nm}$ are strongly dependent on the morphology of the normal fibroblast and the cancerous epithelial (MCF-7) cells [31].

Our hypothesis is that decorating MSNs with different functional groups occur a great impact on biocompatibility of colloidal nanoparticles. In this research, we study and compare the biocompatibility of MSNs with different surface functionalities (amine, carboxyl and polyamine) in both 2D and 3D culture systems. Herein, mesoporous silica nanoparticles were synthesized by template removing method. Then, as illustrated in Fig. 1a, they were modified to affix different functional groups on their surface. The as-prepared MSNs were introduced to 2D and 3D cell culture systems in different concentrations and their effects on the cell morphology and viability in the culture systems were studied. A simple schematic of 2D and 3D cell cultures developed in this work are demonstrated in Fig. $1 \mathrm{~b}$. 
a Bare

Mesoporous Silica Nanoparticles

(MSNs)
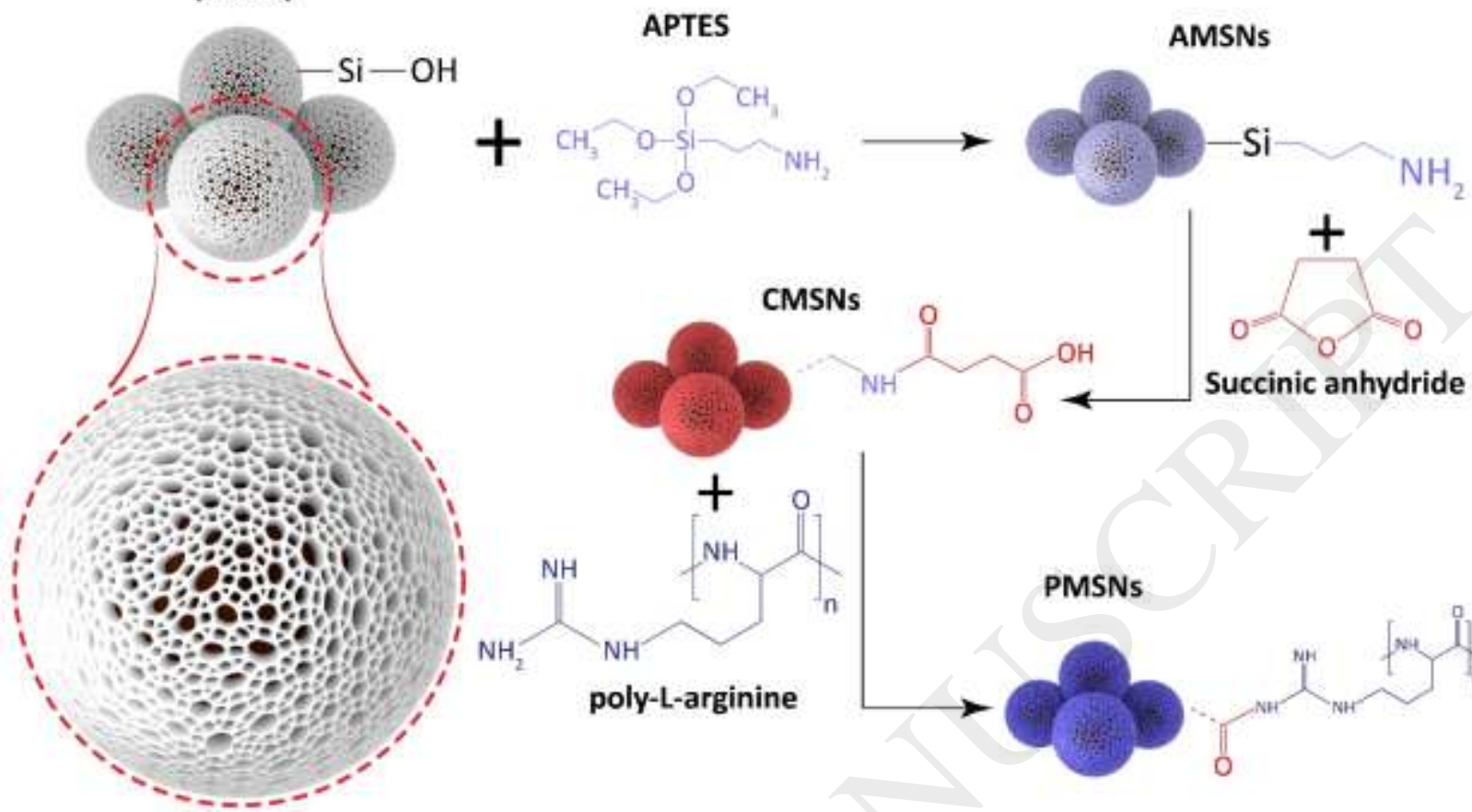

Succinic anhydride

\section{Functionalization}

b

2D culture system

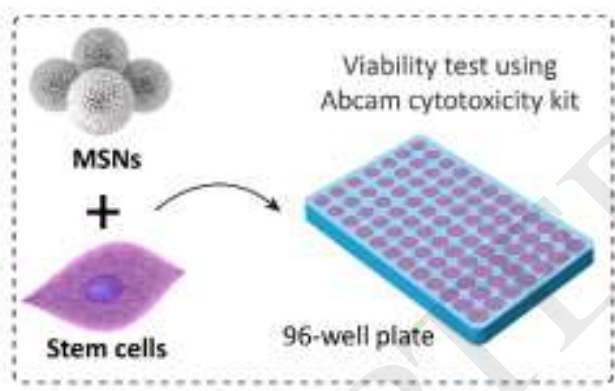


Sigma-Aldrich-33120), poly(L-arginine hydrochloride) (MW = 19000, Alamanda polymers, USA), succinic anhydride (Sigma-Aldrich-239690), acetic acid glacial (Sigma-Aldrich-537020), NHydroxysuccinimide (NHS, Sigma-Aldrich-130672), N-(3-dimethylaminopropyl)-Nethylcarbodiimide hydrochloride (EDC, Sigma-Aldrich-03450), ethanol absolute (VWR chemicals), hydrochloric acid (HCL, 37 \%, Sigma-Aldrich-320331), nitric acid (Merck, Germany), sodium hydroxide (NaOH, Sigma-Aldrich-S0899), and Dulbecco's phosphate-buffered saline (DPBS, Thermo Fisher Scientific) were purchased from the above-noted companies and used as provided. Water was deionized using water purification system (Milli-Q Academic, Millipore, USA).

Human mesenchymal stem cells (hMSCs) were delivered by Lonza Inc. and preserved as freeze stock. Low glucose Dulbecco's modified Eagle's medium with GlutaMAX ${ }^{\mathrm{TM}}$ supplement (DMEM), fetal bovine serum (FBS), and penicillin/streptomycin were purchased from Thermo Fisher Scientific company. Abcam-ab112118 cell cytotoxicity kit were purchased from Abcam company. Nunc-MicroWell 96-well optical-bottom plates were bought from Thermo Fisher Scientific company. LIVE/DEAD ${ }^{\circledR}$ viability assay kit was purchased from Life Technologies and used according to the manufacturer protocol. Silicon isolators (JTR24R-1) were procured from Grace Bio-Labs.

\subsection{MSNs synthesis}

Template removing method was used to synthesize mesoporous silica nanoparticles [32]. Briefly, $100 \mathrm{mg}$ of CTAB as liquid crystal templating agent was dissolved in $48.65 \mathrm{ml}$ of deionized water. The $\mathrm{pH}$ was fine-tuned between 10.5 to 11.5 using sodium hydroxide solution (2 M). TEOS $(1 \mathrm{ml})$ was added dropwise as the silica precursor while the solution was stirred (1500 rpm) at 80 ${ }^{\circ} \mathrm{C}$. After 2 hours, the solution was centrifuged, and the MSNs were subsequently collected from 
the sediment layer. In order to remove the remaining CTAB, the MSNs were washed two times for 8 hours in a $10 \%(\mathrm{v} / \mathrm{v})$ solution of hydrochloric acid in almost pure ethanol, followed by final washing with absolute ethanol and deionized water. They were then kept at 4 ० for further down-stream usages.

\subsection{Surface functionalization of MSNs}

3-(2-aminoethyl amino)propyltrimethoxysilane, succinic anhydride, and poly-L-arginine were used to functionalize MSNs surface with amine, carboxylic and polymeric amine groups, respectively. In order to prepare amine-functionalized MSNs, ethanol-washed MSNs (150 mg) were dispersed in $13.8 \mathrm{ml}$ of absolute ethanol using sonication, then $0.6 \mathrm{ml}$ of deionized water and $0.3 \mathrm{ml}$ acetic acid was added. APTES $(0.3 \mathrm{ml})$ was introduced to the solution at room temperature while being stirred at $1000 \mathrm{rpm}$. Once the reaction was completed, the as-prepared AMSNs were washed twice with ethanol and deionized water and stored in fridge for further use.

To prepare carboxyl-functionalized MSNs, succinic anhydride (200 mg) was added to a synthesis vessel containing DMF (20 ml) stirring at $1000 \mathrm{rpm}$ under nitrogen purge. After $20 \mathrm{~min}$, a suspension of well-dispersed AMSNs in DMF $(20 \mathrm{ml}, 0.5 \% \mathrm{w} / \mathrm{v})$ was added in a drop-wise manner during $10 \mathrm{~min}$ to the first solution while being stirred at $1000 \mathrm{rpm}$. After additional 20 minutes of nitrogen purging, the vessel was sealed with parafilm and left at room temperature for 24 hours. The CMSNs were washed 2 times with DMF, ethanol, and deionized water sequentially and stored in deionized water in fridge for further use.

Deionized water-washed CMSNs were used in order to prepare poly-L-arginine-coated MSNs (PMSNs). For that, CMSNs (50 mg) were dispersed in $10 \mathrm{ml}$ of PBS solution (10 mM) containing $2 \mathrm{mg} \mathrm{NHS}$ and $10 \mathrm{mg}$ EDC. Then, $1.5 \mathrm{ml}$ aliquots of CMSNs suspension were shaken for $7 \mathrm{~min}$. The nanoparticles were separated from each aliquot by centrifugation ( $3 \mathrm{~min}, 5000$ 
$\mathrm{rpm}$ ) and then, were dispersed in $1.5 \mathrm{ml}$ of a previously prepared PBS solution (10 $\mathrm{mM})$ containing poly-L-Arginine $(0.2 \% \mathrm{w} / \mathrm{v})$ and were shaken for 1 hour. Finally, the prepared PMSNs were washed with PBS solution (10 mM) and deionized water 3 times ( $3 \mathrm{~min}, 5000 \mathrm{rpm}$ ) and stored in fridge for further use.

\subsection{MSNs characterization}

To determine the mean diameter of the prepared MSNs, samples were coated with gold $(10 \mathrm{~nm})$ and imaged using SEM (FEI-Quanta 200 ESEM FEG) operating at $10 \mathrm{kV}$. The presented mean diameter was estimated using Fiji, an image processing package for biological-image analysis, for more than 500 nanoparticles [33].

As CTAB is a biologically toxic material, it should be completely removed after the washing step explained in the previous section. In this regard, the samples were freeze-dried and CTAB removal was evaluated with Fourier transform infrared (ATR-FTIR) spectroscopy (PerkinElmer Spectrum 100 FTIR spectrometer, USA). The transmittance spectrum of the respective samples was recorded between 4000 to $600 \mathrm{~cm}^{-1}$.

To validate the successful surface modification of MSNs, FTIR spectra of the prepared samples were recorded using Bruker tensor 27 FTIR spectrometer. To prepare the samples, all four types of MSNS were thoroughly dried on a hotplate at $120^{\circ} \mathrm{C}$ for $2 \mathrm{~h}$. One $\mathrm{mg}$ of each sample was used for preparing $\mathrm{KBr}$ pellets.

Zeta potential of MSNs functionalized with different chemical groups was measured at 25 ${ }^{\circ} \mathrm{C}$ using Malvern Zetasizer device (Nano Series ZS, Malvern Instruments, UK). The hydrodynamic size of MSNs was measured by dynamic light scattering (DLS) using Nano S device (Malvern, UK). To this end, the samples were dispersed in deionized water $(0.1 \mathrm{mg} / \mathrm{l})$ and sonicated for $15 \mathrm{~min}$ before running the test. BET (Brunauer, Emmett, Teller) analysis was employed using a surface 
area analyzer (Micromeritics TriStar II 3020, USA) to determine the specific surface area of the synthesized MSNs. To confirm the mesoporous structure of MSNs, BJH (Barrett-Joyner-Halenda) method revealing MSNs' pore volume and size distribution was employed.

\subsection{Cell culture}

hMSCS were expanded in tissue culture flasks in DMEM supplemented with $10 \%$ FBS and $1 \%$ penicillin/streptomycin and were incubated in a humidified environment with $5 \% \mathrm{CO}_{2}$ at 37 ${ }^{\circ} \mathrm{C}$ until further use. Cells were used at passage 3-5 for all cell toxicity and viability tests.

\subsection{Cell encapsulation}

The prepolymer solution containing MSNs of different concentrations was mixed with hMSCs to obtain the final concentration of $10^{6}$ cells $/ \mathrm{ml}$ of hydrogel. Then, the prepolymer solution was deposited using an automated system (Eppendorf Xplorer, H31141F, Eppendorf, Germany) into silicon isolators ( $2 \mathrm{~mm}$ diameter $\times 1 \mathrm{~mm}$ depth) which previously sterilized and mounted on glass slides. To crosslink the polymeric chains of alginate with the final concentration of $1 \% \mathrm{w} / \mathrm{v}$ and make the cell-laden hydrogels, each microwell was covered by $10-20 \mu \mathrm{L}$ of a $\mathrm{CaCl}_{2}$ solution ( $2 \% \mathrm{w} / \mathrm{v})$. After 5 minutes, to remove the excess salt, the as-prepared hydrogels were washed twice using DPBS and covered with enough complete medium. The samples were incubated in humidified environment with $5 \% \mathrm{CO}_{2}$ at $37{ }^{\circ} \mathrm{C}$ during which the medium was changed every 3-5 days.

\subsection{Viability studies}

To monitor the cytocompatibility of MSNs, the respected tests were performed in 2D and $3 D$ cell culture systems. The cytotoxicity assays in 2D cell cultures were conducted using Abcam cytotoxicity kit as suggested in the manufacturer protocol. Briefly, cells were seeded at the concentration of $5 \times 10^{4}$ cells $/ \mathrm{ml}$ in 96 -well plates and were incubated for one day. Then, the 
media were replaced with $100 \mu$ l of fresh media containing the respected amount of MSNs. After 2 days of incubation, $20 \mu \mathrm{l}$ of the assay solution was added to each well and the samples were incubated for one more day. The media $(100 \mu l)$ were transferred to new well plates and the absorbance was recorded at $570 \mathrm{~nm}$ and $605 \mathrm{~nm}$. The cell viability was then calculated according to the following equation:

$$
\text { Cell viability }(\%)=\left(R_{\text {sample }}-R_{\circ}\right) /\left(R_{\text {control }}-R_{0}\right) \times 100
$$

here, $R_{\text {sample }}$ is the absorbance ratio $\left(\mathrm{OD}_{570} / \mathrm{OD}_{605}\right)$ of samples cultured with MSNs. $R_{\text {control }}$ is the absorbance ratio $\left(O D_{570} / O D_{605}\right)$ for the samples cultured in normal media. $R_{o}$ is the average of the absorbance ratio of the control samples containing no cells.

Fluorescent staining and imaging were applied to determine how MSNs concentration and surface chemistry affect hMSCs morphology and viability. hMSCs were seeded in a 48-well plate $\left(2 \times 10^{4}\right.$ per well) by dispensing $250 \mu \mathrm{l}$ media and incubated for one day. The old media were changed with the media containing the respected nanoparticles. After $48 \mathrm{~h}$ of incubation, media were removed and $70 \mu \mathrm{l}$ of previously prepared LIVE/DEAD ${ }^{\circledR}$ viability assay solution was added to each well. Using this assay, live and dead cells are stained with calcein-AM (green) and ethidium homodimer-1 (red), respectively. Then, a confocal microscope (CLSM, Zeiss LSM 700, Germany) was employed to image the stained cells.

To investigate the biocompatibility of the hydrogel nanocomposite in 3D culture system, the encapsulated cells were stained after being cultured for $1,3,7$, and 14 days using LIVE/DEAD $^{\circledR}$ viability assay kit and the suggested protocol by the manufacturer. The live and dead cells were imaged using a confocal laser-scanning microscope and the images were analyzed by CellProfiler software. To this end, the red and green channels were first separated using the built-in modules in the software, and the cells in each color channel (green for live cells and red for dead cells) 
were identified and counted. Finally, the following equation was used to evaluate the cell viability:

$$
\text { Viability }(\%)=\frac{\text { Number of live cells }}{\text { Total cell number }} \times 100
$$

\subsection{Cellular uptake of MSNs}

To measure cellular uptake of MSNs, hMSCs were seeded at $2 \times 10^{5}$ cells/flask in T25 flasks. After one day, the cells were treated with MSNs of different surface chemistries (100 $\mu \mathrm{g} / \mathrm{ml}$ ) for two days. As the control sample, the same number of cells were cultured in a flask with no treatment. To remove any free MSNs, media was removed and the cells were washed with PBS twice; after which the cells were harvested by trypsinization and centrifugation. The precipitated cells were resuspended in PBS for cell counting. Then, the pellet was dissolved in $500 \mu \mathrm{l}$ of concentrated nitric acid $(100 \% \mathrm{v} / \mathrm{v})$. Afterward, the final volume of each sample reached to $4 \mathrm{ml}$ using $\mathrm{DI}$ water and was incubated at $50{ }^{\circ} \mathrm{C}$ for $30 \mathrm{~min}$. The samples were stored in the fridge until their introduction to inductively coupled plasma optical emission spectroscopy instrument (ICP-OES, Arcos, Spectro, Germany) for detection of Si internalization by cells.

\subsection{Statistical analysis}

To perform statistical analysis of the acquired data GraphPad Prism 7.01 software was employed (San Diego, USA). All numerical results were reported as mean \pm standard deviation and Gaussian distribution was evaluated using Shapiro-Wilk normality test. Using BrownForsythe and Bartlett's tests, homogeneity of variances was evaluated, and for data groups in compliance with the prerequisites of one-way ANOVA, the significance of difference was examined through one-way ANOVA and Tukey's post hoc test. Otherwise, the Kruskal-Wallis nonparametric test followed by Dunn's multiple comparison test was performed. The statistical 
significance levels were presented as $*(p<0.05), * *(p<0.01), * * *(p<0.001)$, and $* * * *(p<0.0001)$.

\section{Results and discussion}

\subsection{MSNs characterization}

Images taken by scanning electron microscopy (SEM) indicated that the synthesized MSNs featured spherical shape with uniform diameter (Fig. 3a). To measure the mean diameter of MSNs and investigate their monodispersity, Fiji analysis program was employed (Fig. 3b). The acquired results showed a mean diameter of $88 \pm 13 \mathrm{~nm}$ with a PDI value of 0.15 implying that the synthesized MSNs are monodisperse and have a size range that enables a high cellular uptake [34]. From the FTIR results (Fig. 3c), we noticed that the two intense peaks at $2854 \mathrm{~cm}^{-1}$ and 2924 $\mathrm{cm}^{-1}$ which represent the symmetric and asymmetric stretching vibrations of the methylene chains of $C T A B$ vanish completely through ethanol-HCl treatment [35]. This implies that the synthesized MSNs are free of cytotoxic precursors.

An important characteristic of nanoparticles is their surface charge; which can significantly influence their interactions and uptake by cells as well as their cytocompatibility [3638]. Because of the innate negative charge of the cells membrane, positively charged nanoparticles result in higher cellular uptake making them more efficient carriers for delivery of biomolecules [38]. Nevertheless, when compared to their low charged counterparts, the higher cytotoxicity of highly-charged polycationic constructs has previously been reported [37]. Fig. 4a

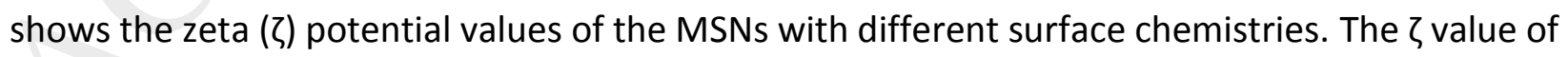
$-18 \mathrm{mV}$ for BMSNs is attributed to presence of hydroxyl groups on their surface. Suggesting successful surface functionalization of BMSNs, this value was changed to about $+26,-20,+43 \mathrm{mV}$ once modified with amine, carboxyl, and polyamine groups, respectively. 

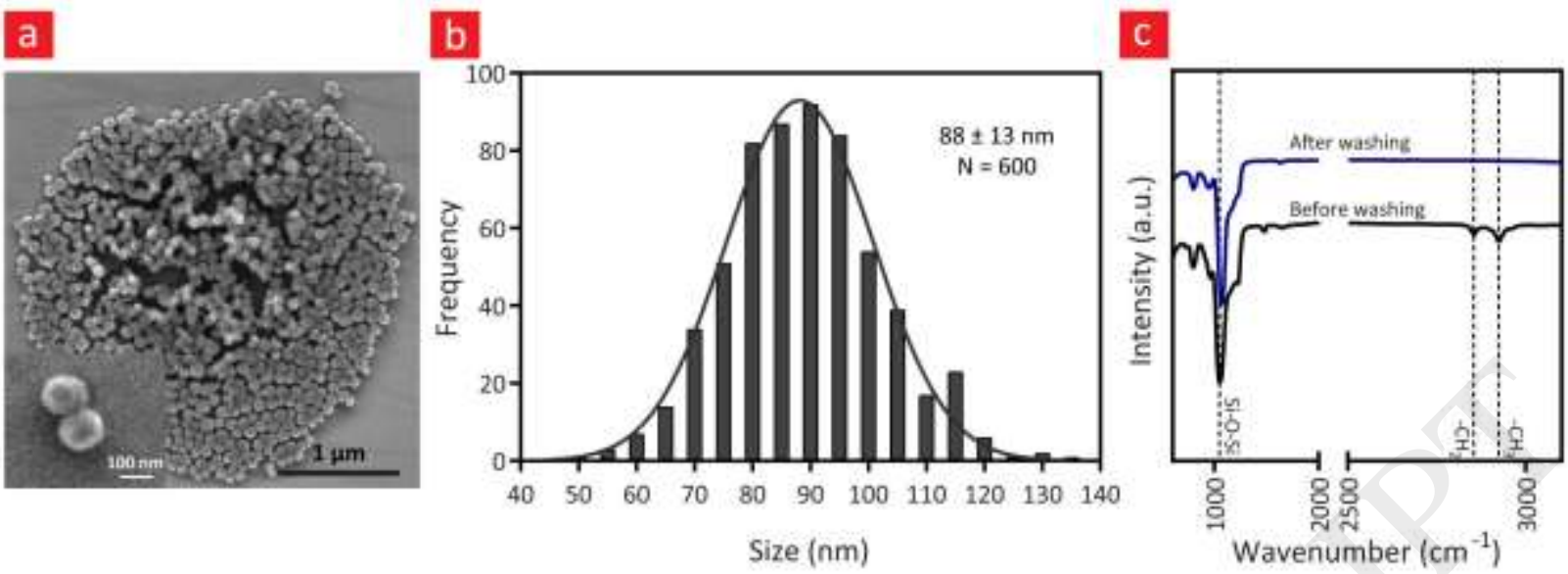

Fig. 3: a) SEM micrograph showing mesoporous silica nanoparticles. b) Size distribution of synthesized silica nanoparticles. c) FT-IR spectra showing the elemination of methyle, methylen, and amine groups related to CTAB removal from the as-prepared MSNs by treating with ethanol-HCl solution.

Furthermore, DLS analysis was employed to explore the effect of the surface chemistry on the dispersion/agglomeration of MSNs. Fig. 4b shows the MSNs diameter distribution on which regression of gaussian equation was applied. DLS measures the hydrodynamic diameter of MSNs, which is strongly dependent on the solvent and its layers associated with MSNs while in microscopy techniques, the actual size of MSNs is measured in its dry state [39]. The hydrodynamic diameters of BMSNs, AMSNs, and CMSNs were obtained $240 \pm 27,276 \pm 31$, and $199 \pm 22 \mathrm{~nm}$, respectively (Fig. 4b). The significant difference in the hydrodynamic size of PMSNs' diameter $(103 \pm 10 \mathrm{~nm})$ in comparison to other MSNs might be attributed to its high zeta potential value $(+43 \mathrm{mV})$ which supports their good dispersion and improves the PMSNs colloidal stability.

Fig. 4c depicts FTIR spectra for the as-prepared MSNs. Siloxanes as the main groups in silica nanoparticles were characterized by stretching frequencies of $\mathrm{Si}-\mathrm{O}-\mathrm{Si}$ linkage in the range of $1100-1000 \mathrm{~cm}^{-1}$ [40]. Silanol (Si-OH) groups existing on BMSNs surface involve the hydroxyl (OH) groups stretch at $3700-3200 \mathrm{~cm}^{-1}[40-42]$. The weak band at $1410 \mathrm{~cm}^{-1}$ confirmed the Si-C bond in all the surface modified MSNs, as described previously [40], which is a result of its functionalization with APTES. As OH moieties on silica surface were decorated by amine groups, 
the width of its respected broad band $\left(3700-3200 \mathrm{~cm}^{-1}\right)$ was reduced and replaced with amine $\left(\mathrm{NH}_{2}\right)$ group stretching starting from $3300 \mathrm{~cm}^{-1}$ [40]. The observed weak signal at $2940 \mathrm{~cm}^{-1}$ corresponding to stretching vibration modes of aliphatic $\mathrm{C}-\mathrm{H}$ bonds was emerged after aminefunctionalization of BMSNs and intensified after consequential functionalization [42]. In response to MSNs modification with carboxylic acids, a very broad band related to $\mathrm{OH}$ groups starting from $3200 \mathrm{~cm}^{-1}$ was shown up. The presence of carboxylic groups was also confirmed by a sharp band at $1720 \mathrm{~cm}^{-1}$ corresponding to the antisymmetric stretch of carbonyl groups in CMSNs [40]. Furthermore, the peak at $2979 \mathrm{~cm}^{-1}$ was related to $\mathrm{OH}$ groups in carboxylic acid dimers [40]. Ultimately, the successful decoration of MSNs by poly-L-arginine was validated by peaks at 1642 $\mathrm{cm}^{-1}$ and $1555 \mathrm{~cm}^{-1}$ corresponding to amide I and amide II, respectively [40]. The weak stretching band of $\mathrm{NH}$ also was appeared in the region of $3325-3500 \mathrm{~cm}^{-1}[40]$. 
a

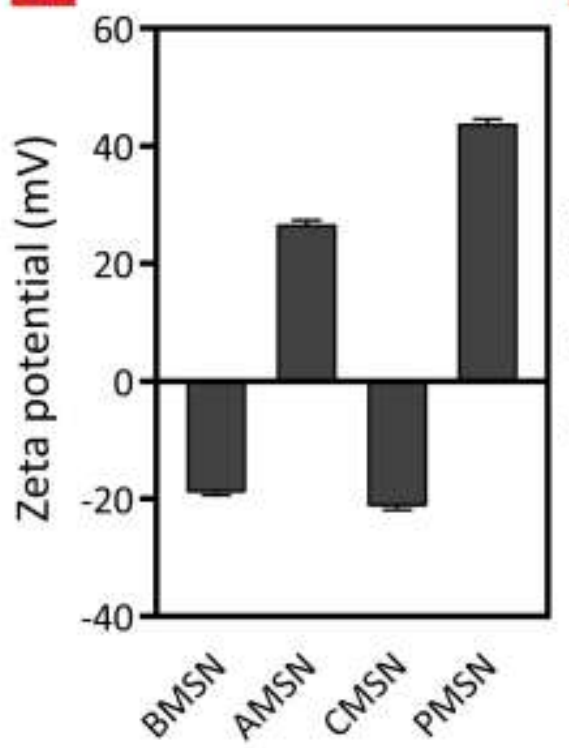

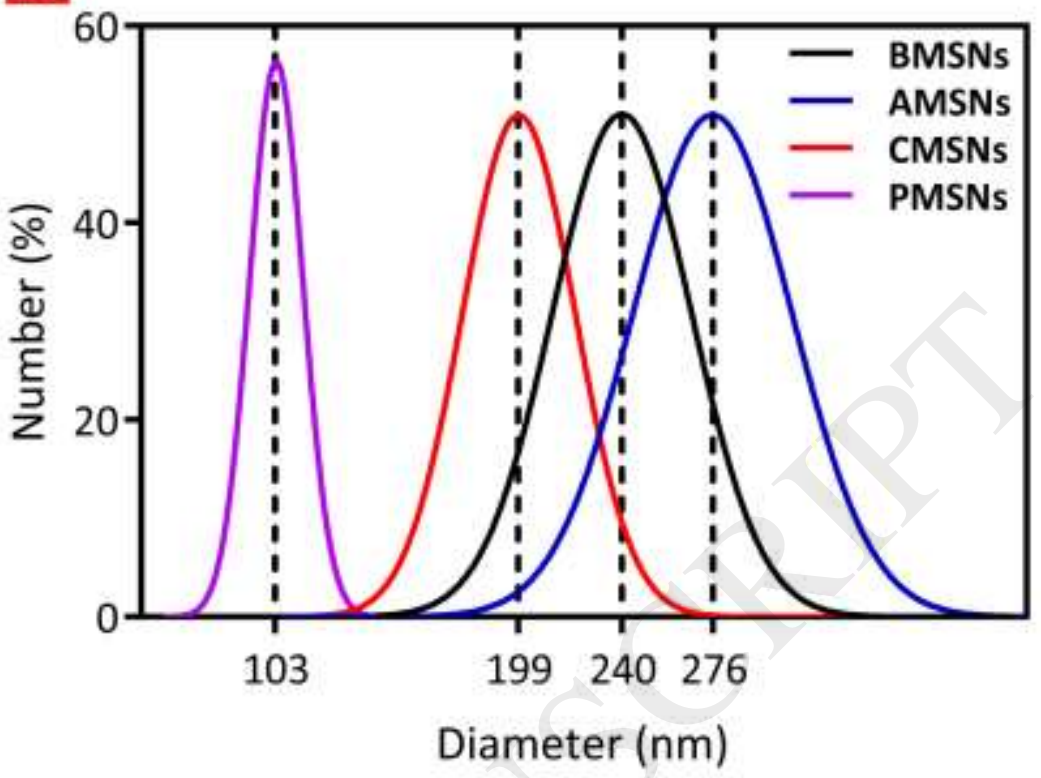

C

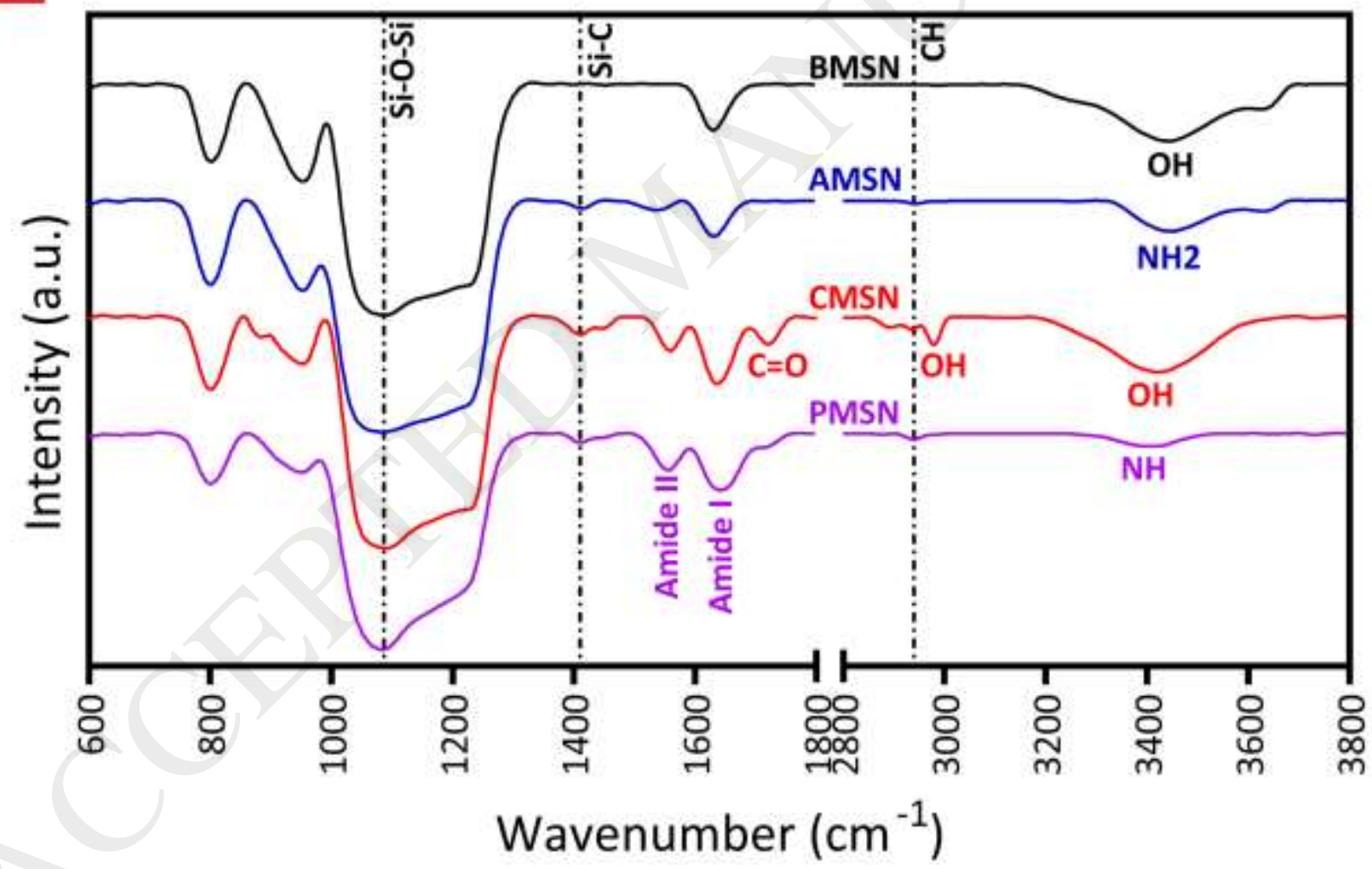

Fig. 4: a) Zeta potential of silica nanopartciles in aqueous solution confirming the favored functinalization. b) Hydrodynamic diameter of different MSNs acquired from dynamic light scattering. c) FT-IR spectra of MSNs of different surface chemistries (BMSNs, AMSNs, CMSNs and PMSNs).

In BET analysis, nitrogen isotherms of MSNs showed a great difference following various surface modifications. As results presented in table 1 show, the BET surface area and the total pore volume are dramatically decreased after consecutive modifications. For example, the BET 
surface area decreased from $734 \mathrm{~m}^{2} / \mathrm{g}$ for BMSNs to $134 \mathrm{~m}^{2} / \mathrm{g}$ for PMSNs which confirms the successful binding of polymeric groups to both MSNs' internal and external surfaces.

Table 1. Structural properties of the synthesized MSNs

\begin{tabular}{|c|c|c|c|c|c|}
\hline Nanoparticle type & $\mathrm{S}_{\mathrm{BET}}^{\mathrm{a}}\left(\mathrm{m}^{2} / \mathrm{g}\right)$ & $\mathrm{V}_{\mathrm{t}}^{\mathrm{b}}\left(\mathrm{cm}^{3} / \mathrm{g}\right)$ & $\mathrm{d}_{\mathrm{BJH}}^{\mathrm{c}}(\mathrm{nm})$ & $\zeta^{d}(\mathrm{mV})$ & $\mathrm{d}_{\mathrm{DLS}}^{\mathrm{e}}(\mathrm{nm})$ \\
\hline BMSNs & 734 & 0.713 & 2.5 & -18 & $240 \pm 27$ \\
\hline AMSNs & 579 & 0.585 & 2.3 & +26 & $276 \pm 31$ \\
\hline CMSNs & 486 & 0.461 & 2.1 & -20 & $199 \pm 22 \mathrm{~nm}$ \\
\hline PMSNs & 134 & 0.179 & 0.9 & +43 & $103 \pm 10 \mathrm{~nm}$ \\
\hline \multicolumn{6}{|c|}{$\begin{array}{l}\text { a Total surface area from } B E T \text { analysis } \\
\text { b Total pore volume calculated from nitrogen isotherm at } \mathrm{P} / \mathrm{P}_{0}=0.98 \\
\text { c BJH adsorption average pore width } \\
\text { d Zeta potential } \\
\text { e Hydrodynamic diameter }\end{array}$} \\
\hline
\end{tabular}

\subsection{Cytotoxicity and cell morphology}

In order to determine the nanoparticle toxicity on 2D cultured hMSCs, a calorimetric kit was used to assay the viability by measuring the absorption ratio - a number that is directly proportional to the number of living cells. The presented results in Fig. 5a indicated that there are no cytotoxic effects observed in the MSNs concentration of $10 \mu \mathrm{g} / \mathrm{ml}$. As the concentration increases to $50 \mu \mathrm{g} / \mathrm{ml}$, the MSNs with the highest positive charge (PMSNs) showed significant cytotoxicity effects. In contrast, there was no cytotoxicity effect observed for BMSNs and CMSNs, even at the highest employed concentrations $(1000 \mu \mathrm{g} / \mathrm{ml})$. Meanwhile, no cytotoxicity occurred when applying AMSNs in concentrations up to $500 \mu \mathrm{g} / \mathrm{ml}$. Therefore, AMSNs are suitable nanocarriers considering their non-cytotoxic property at relatively high concentrations and also a positive surface charge which result in higher cellular uptake and more efficient delivery of biomolecules [37].

To investigate in more detail what impact MSNs with different surface chemistries have 
on cell toxicity, hMSCs treated with different concentrations of MSNs were stained using calceinAM and ethidium homodimer-1 (Fig. 5b-f). Calcein-AM unravels the morphology of the living cells; while, ethidium homodimer-1 stains the nuclei of the dead cells. The fluorescent images showed almost no changes on the morphology of hMSCs treated even with the highest concentrations of BMSNs, AMSNs, and CMSNs (Fig. 5c-e) in comparison to control sample (Fig. 5b). However, it was observed that PMSNs disrupt the plasma-membrane integrity and spindleshape morphology of the hMSCs (Fig. 5f). It is reported that surpassing a threshold of surface charge density may cause acute disruption of the membrane and therefore an intense cytotoxicity [43]. Poly-L-arginine may also, similar to polyethylene imine, cause enhanced cell uptake and subsequently destabilization of lysosomes within cells resulting in their content discharge in cytosol and ultimately cell apoptosis [44-47]. To further delve on these hypotheses, the effect of the different surface chemistries on MSNs uptake by hMSCs was assessed using ICPOES technique. The obtained results revealed that hMSCs uptake PMSNs significantly (29.6 $\mathrm{pg} / \mathrm{cell})$ more than that of the BMSNs (1 pg/cell), AMSNs (2.3 pg/cell) and CMSNs (0.9 pg/cell); that most likely caused a $50 \%$ reduction in the cell viability by PMSNs at $100 \mu \mathrm{g} / \mathrm{ml}$. Although PMSNs were observed to be highly cytotoxic at high concentrations, they showed great biocompatibility at $10 \mu \mathrm{g} / \mathrm{ml}$. Therefore, this concentration might be applicable in controlled release delivery systems considering that the polymeric chains on the PMSNs surface may provide higher loading capacity than their counterparts. Moreover, L-arginine groups were reported to bestow many therapeutic benefits ranging from cancer immunotherapy [48] and anti-inflammation [49] to homeostasis [50,51]. 


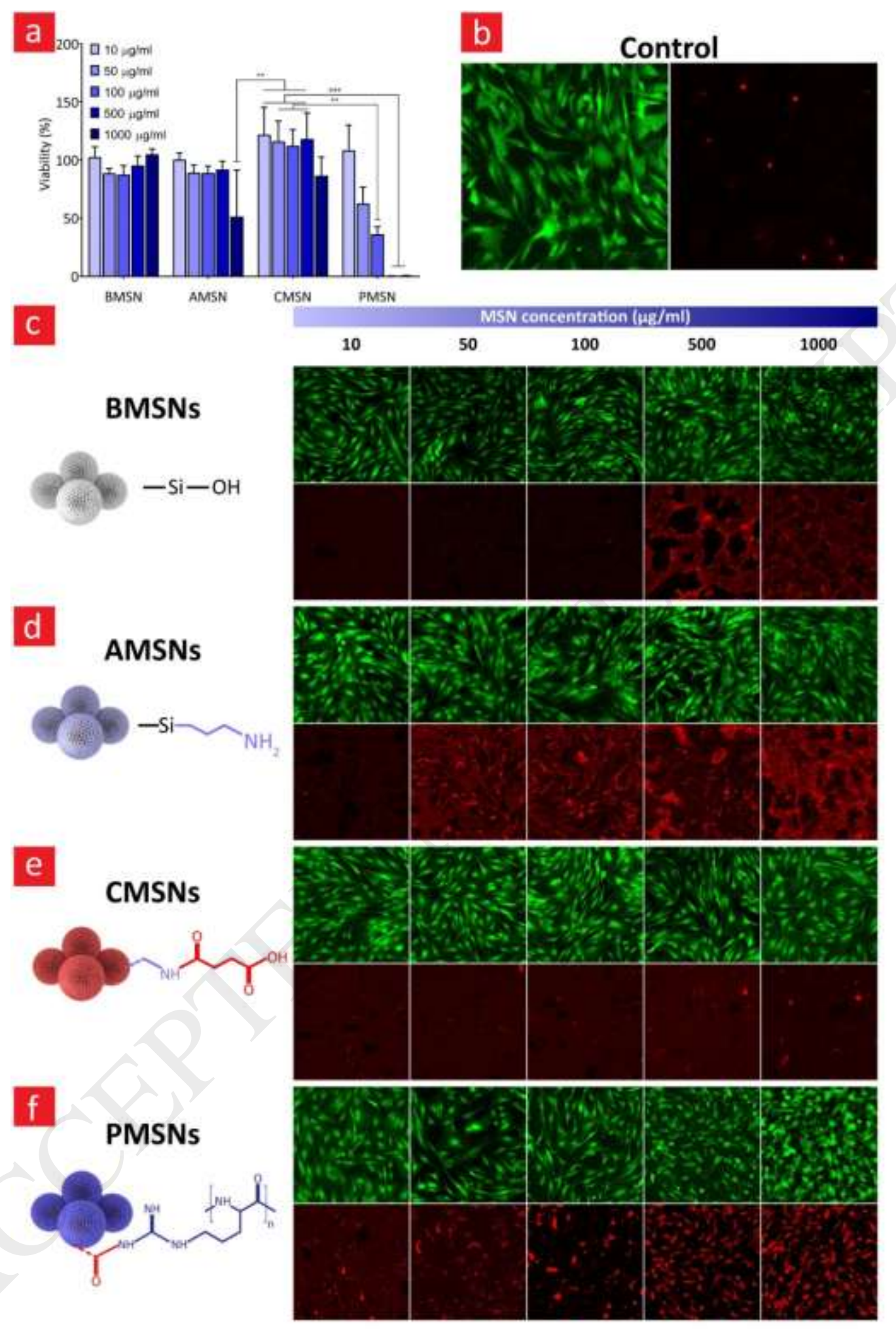

Fig. 5: a) The viability (\%) of the 2D cultured hMSCs after being in contact with different concentartions of MSNs for 48 h, measured using Abcam-ab112118 cell cytotoxicity kit. b) Imaging of hMSCs cultured in 2D culture containing complete media with fluorescent microscopy (10X objective); green and red colors represents the live and dead cells stained with calcein-AM (left) and ethidium homodimer-1 (right), respectively. c-f) The fluorescent images of hMSCs after being in contact with different concentartions of MSNs for $48 \mathrm{~h}$ stained with calcein-AM (green) and ethidium homodimer-1 (red). 


\subsection{Cell viability in 3D environment}

As the native cells in the body live in a 3D microenvironment and their phenotype and expression of transcription factors are completely different from that in 2D culture conditions $[52,53]$, the viability of hMSCs encapsulated in alginate nanocomposite hydrogels containing different percentage of MSNs was studied. Fig. 6a-b depicts the live and dead cells after 2 weeks of culture in control (alginate) and nanocomposite hydrogels. Fig. 6c presents the results obtained on the hMSCs viability after 1, 3, 7, and 14 days cultures in different nanocomposite hydrogels using analysis of fluorescent images. These results indicate that the cell viability was almost over $70 \%$ for all the combinations after 7 days of culture. This high viability of hMSCs was maintained after 2 weeks for all the combinations except the hydrogels incorporated with more than $5 \%$ of CMSNs and PMSNs. This shows higher cytotoxic effect of CMSNs in 3D microenvironment when compared to $2 \mathrm{D}$ condition, which might be attributed to the different morphology of the cells in different culture systems, imposed by microenvironmental differences cells would sense in these two systems [31]. The spherical morphology of the hMSCs in 3D culture system (Fig. 6a-b) may imply unsuitable conditions in the microenvironments of the cultured cells in hydrogels incorporated with 5\% of CMSNs and PMSNs, as described in the literature [54]. The more extensive impact of high concentrations of MSNs, in particular for CMSNs in 3D culture in comparison to that in 2D culture, can be due to this fact that the cells surface is exposed more to nanoparticles in 3D culture than in 2D culture. This can provide a higher chance for the interaction between cells and nanoparticles and consequently result in stronger impact on the cells in the 3D culture system. In this regard, future studies investigating cellular uptake for MSNs with different surface chemistries in 3D cultures and exact mechanisms of different cytotoxicity responses in different culture systems are of high importance. Moreover, there are some studies 
reporting the differentiation-directing potential of small functional groups existing in the cell microenvironment [55-57]. In a study by Benoit et al. [57], for instance, a set of hydrophilic and hydrophobic functional groups inserted in a PEG-based matrix was used to induce differentiation of hMSCs toward osteogenesis, chondrogenesis, and adipogenesis. It has been shown that carboxylic groups mimicking the functional groups of glycosaminoglycans, the main part of native cartilage, upregulated expression of collagen II; whereas the hydrophobic moieties improved adipogenesis and amine groups showed no considerable changes [57]. Therefore, future studies assessing this potential of MSNs are highly suggested in order to further highlight the prospective application of the functionalized MSNs towards directing the stem cells differentiation. 


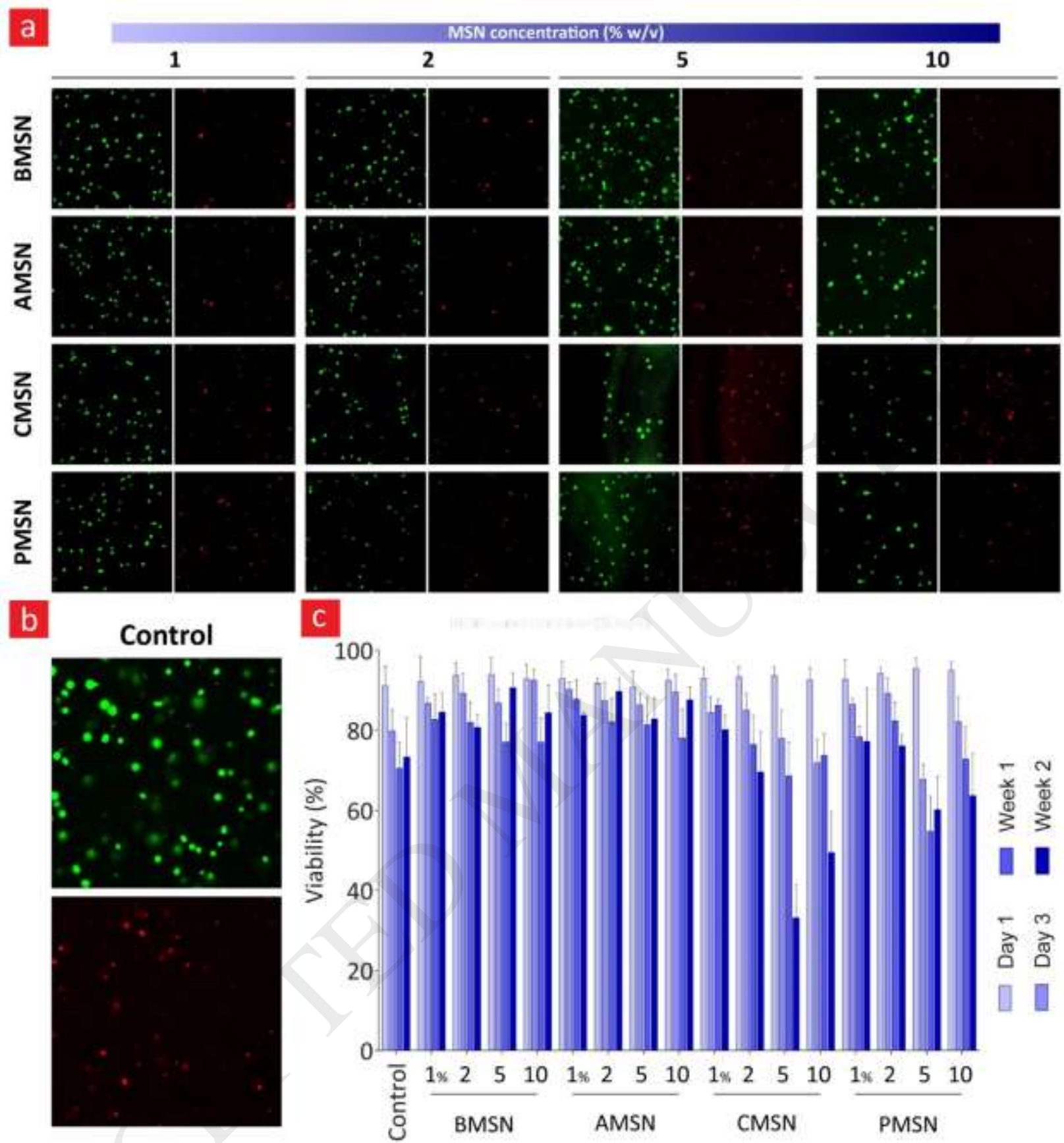

Fig. 6: Live (green) and dead (red) cells visualized by confocal fluorescent microscopy after 2 weeks of culture in (a) nanocomposite hydrogels comprising different percentage of MSNs of various surface chemistries and (b) pure alginate hydrogel. c) The results of viability assay for hMSCs encapsulated in the alginate-based nanocomposite hydrogels after 1, 3, 7, and 14 days culture.

\section{Conflicts of interest}

There are no conflicts of interest to declare.

\section{Conclusion}

Herein, we have demonstrated the viability of hMSCs cultured in 2D and 3D systems in 
the presence of MSNs with various surface chemistries. BMSNs and AMSNs showed no significant toxicity in the different concentrations tested in this study on hMSCs encapsulated in alginate hydrogels. In contrary, CMSNs and PMSNs showed significant cytotoxic effects at concentrations higher than 5\% in such 3D cultures. It was demonstrated that the cellular uptake of PMSNs was greatly higher in comparison to those of other MSNs as a result of considerably high positive charge of PMSNs. That caused a significant decrease in the viability of cells incubated with even low concentrations of PMSNs.

Further studies are needed to investigate in detail the mechanisms governing the effect of nanoparticles on living cells, in particular in 3D cell culture systems. The high viability of the hMSCs cultured along with bare and amine-modified MSNs (BMSNs and AMSNS, respectively) in both $2 \mathrm{D}$ and $3 \mathrm{D}$ systems presents the potential of such nanoparticles as promising carriers of different types of biomolecules, such as growth and differentiation factors for a wide range of biomedical applications.

\section{Acknowledgment}

ADP would like to acknowledge the Danish Council for Independent Research (Technology and Production Sciences, 5054-00142B), Gigtforeningen (R139-A3864) and the Villum Foundation (10103). This work is also part of the VIDI research programme with project number R0004387, which is (partly) financed by the Netherlands Organisation for Scientific Research (NWO).

\section{References}

[1] K. Ghosal, K. Sarkar, Biomedical Applications of Graphene Nanomaterials and Beyond, ACS Biomater. Sci. Eng. $4 \quad$ (8) 2653-2703. https://doi.org/10.1021/acsbiomaterials.8b00376.

[2] S. Das, S. Mitra, S.M.P. Khurana, N. Debnath, Nanomaterials for biomedical applications, Frontiers in Life Science 7 (3-4) (2014) 90-98. https://doi.org/10.1080/21553769.2013.869510.

[3] M.D. Dozois, L.C. Bahlmann, Y. Zilberman, X. Tang, Carbon nanomaterial-enhanced scaffolds for the creation of cardiac tissue constructs: A new frontier in cardiac tissue engineering, 
Carbon 120 (2017) 338-349. https://doi.org/10.1016/j.carbon.2017.05.050.

[4] R. Vankayala, K.C. Hwang, Near-Infrared-Light-Activatable Nanomaterial-Mediated Phototheranostic Nanomedicines: An Emerging Paradigm for Cancer Treatment, Adv. Mater. Weinheim. 30 (23) (2018) e1706320. https://doi.org/10.1002/adma.201706320.

[5] M. Mehrali, A. Thakur, C.P. Pennisi, S. Talebian, A. Arpanaei, M. Nikkhah, A. DolatshahiPirouz, Nanoreinforced Hydrogels for Tissue Engineering: Biomaterials that are Compatible with Load-Bearing and Electroactive Tissues, Adv. Mater. Weinheim. 29 (8) (2017). https://doi.org/10.1002/adma.201603612.

[6] A.K. Gaharwar, A. Arpanaei, T.L. Andresen, A. Dolatshahi-Pirouz, 3D Biomaterial Microarrays for Regenerative Medicine: Current State-of-the-Art, Emerging Directions and Future Trends, Adv. Mater. Weinheim. 28 (4) (2016) 771-781. https://doi.org/10.1002/adma.201503918.

[7] M. Mehrali, A.R. Akhiani, S. Talebian, M. Mehrali, S.T. Latibari, A. Dolatshahi-Pirouz, H.S.C. Metselaar, Electrophoretic deposition of calcium silicate-reduced graphene oxide composites on titanium substrate, Journal of the European Ceramic Society 36 (2) (2016) 319-332. https://doi.org/10.1016/j.jeurceramsoc.2015.08.025.

[8] T. Jensen, T. Jakobsen, J. Baas, J.V. Nygaard, A. Dolatshahi-Pirouz, M.B. Hovgaard, M. Foss, C. Bünger, F. Besenbacher, K. Søballe, Hydroxyapatite nanoparticles in poly-D,L-lactic acid coatings on porous titanium implants conducts bone formation, J. Biomed. Mater. Res. A 95 (3) (2010) 665-672. https://doi.org/10.1002/jbm.a.32863.

[9] J. Liu, Q. Peng, Protein-gold nanoparticle interactions and their possible impact on biomedical applications, Acta Biomater. $55 \quad$ (2017) 13-27. https://doi.org/10.1016/j.actbio.2017.03.055.

[10] D. Shi, M.E. Sadat, A.W. Dunn, D.B. Mast, Photo-fluorescent and magnetic properties of iron oxide nanoparticles for biomedical applications, Nanoscale 7 (18) (2015) 8209-8232. https://doi.org/10.1039/c5nr01538c.

[11] L.S. Arias, J.P. Pessan, A.P.M. Vieira, T.M.T.d. Lima, A.C.B. Delbem, D.R. Monteiro, Iron Oxide Nanoparticles for Biomedical Applications: A Perspective on Synthesis, Drugs, Antimicrobial Activity, and Toxicity, Antibiotics (Basel) 7 (2) (2018). https://doi.org/10.3390/antibiotics7020046.

[12] X.Y. Ma, Y.F. Feng, T.S. Wang, W. Lei, X. Li, D.P. Zhou, X.X. Wen, H.L. Yu, L.B. Xiang, L. Wang, Involvement of FAK-mediated BMP-2/Smad pathway in mediating osteoblast adhesion and differentiation on nano-HA/chitosan composite coated titanium implant under diabetic conditions 6 (1) (2018) 225-238. https://doi.org/10.1039/c7bm00652g.

[13] L. Tao, L. Zhonglong, X. Ming, Y. Zezheng, L. Zhiyuan, Z. Xiaojun, W. Jinwu, In vitro and in vivo studies of a gelatin/carboxymethyl chitosan/LAPONITE ${ }^{\circledR}$ composite scaffold for bone tissue engineering, RSC Adv. 7 (85) (2017) 54100-54110. https://doi.org/10.1039/C7RA06913H.

[14] S. Buyuksungur, T. Endogan Tanir, A. Buyuksungur, E.I. Bektas, G. Torun Kose, D. Yucel, T. Beyzadeoglu, E. Cetinkaya, C. Yenigun, E. Tönük, V. Hasirci, N. Hasirci, 3D printed poly( $\epsilon-$ caprolactone) scaffolds modified with hydroxyapatite and poly(propylene fumarate) and 
their effects on the healing of rabbit femur defects, Biomaterials Science 5 (10) (2017) 21442158. https://doi.org/10.1039/c7bm00514h.

[15] M. Hasany, A. Thakur, N. Taebnia, F.B. Kadumudi, M.A. Shahbazi, M.K. Pierchala, S. Mohanty, G. Orive, T.L. Andresen, C.B. Foldager, S. Yaghmaei, A. Arpanaei, A.K. Gaharwar, M. Mehrali, A. Dolatshahi-Pirouz, Combinatorial Screening of Nanoclay Reinforced Hydrogels: A Glimpse of the "Holy Grail" in Orthopedic Stem Cell Therapy? ACS Appl. Mater. Interfaces (2018). https://doi.org/10.1021/acsami.8b11436.

[16] J.M. Rosenholm, J. Zhang, M. Linden, C. Sahlgren, Mesoporous silica nanoparticles in tissue engineering--a perspective, Nanomedicine (Lond) 11 (4) (2016) 391-402. https://doi.org/10.2217/nnm.15.212.

[17] L. Palanikumar, J. Kim, J.Y. Oh, H. Choi, M.-H. Park, C. Kim, J.-H. Ryu, Hyaluronic AcidModified Polymeric Gatekeepers on Biodegradable Mesoporous Silica Nanoparticles for Targeted Cancer Therapy, ACS Biomater. Sci. Eng. (2018). https://doi.org/10.1021/acsbiomaterials.8b00218.

[18] F. Tang, L. Li, D. Chen, Mesoporous silica nanoparticles: Synthesis, biocompatibility and drug delivery, Adv. Mater. Weinheim. 24 (12) (2012) 1504-1534. https://doi.org/10.1002/adma.201104763.

[19] I.I. Slowing, J.L. Vivero-Escoto, C.-W. Wu, V.S.-Y. Lin, Mesoporous silica nanoparticles as controlled release drug delivery and gene transfection carriers, Adv. Drug Deliv. Rev. 60 (11) (2008) 1278-1288. https://doi.org/10.1016/j.addr.2008.03.012.

[20] Z. Li, J.C. Barnes, A. Bosoy, J.F. Stoddart, J.I. Zink, Mesoporous silica nanoparticles in biomedical applications, Chem. Soc. Rev. 41 (7) (2012) 2590-2605. https://doi.org/10.1039/c1cs15246g.

[21] W. Fan, B. Shen, W. Bu, F. Chen, Q. He, K. Zhao, S. Zhang, L. Zhou, W. Peng, Q. Xiao, D. Ni, J. Liu, J. Shi, A smart upconversion-based mesoporous silica nanotheranostic system for synergetic chemo-/radio-/photodynamic therapy and simultaneous MR/UCL imaging, Biomaterials $\quad 35 \quad$ (32) 8992-9002. https://doi.org/10.1016/j.biomaterials.2014.07.024.

[22] L. Miller, G. Winter, B. Baur, B. Witulla, C. Solbach, S. Reske, M. Lindén, Synthesis, characterization, and biodistribution of multiple 89Zr-labeled pore-expanded mesoporous silica nanoparticles for PET, Nanoscale 6 (9) (2014) 4928-4935. https://doi.org/10.1039/c3nr06800e.

[23] R. Kumar, I. Roy, T.Y. Ohulchanskky, L.A. Vathy, E.J. Bergey, M. Sajjad, P.N. Prasad, In vivo biodistribution and clearance studies using multimodal organically modified silica nanoparticles, ACS Nano 4 (2) (2010) 699-708. https://doi.org/10.1021/nn901146y.

[24] V. Mamaeva, J.M. Rosenholm, L.T. Bate-Eya, L. Bergman, E. Peuhu, A. Duchanoy, L.E. Fortelius, S. Landor, D.M. Toivola, M. Lindén, C. Sahlgren, Mesoporous silica nanoparticles as drug delivery systems for targeted inhibition of Notch signaling in cancer, Mol. Ther. 19 (8) (2011) 1538-1546. https://doi.org/10.1038/mt.2011.105.

[25] M. Mehrasa, M.A. Asadollahi, K. Ghaedi, H. Salehi, A. Arpanaei, Electrospun aligned PLGA 
and PLGA/gelatin nanofibers embedded with silica nanoparticles for tissue engineering, Int. J. Biol. Macromol. 79 (2015) 687-695. https://doi.org/10.1016/j.ijbiomac.2015.05.050.

[26] Z. Luo, Y. Deng, R. Zhang, M. Wang, Y. Bai, Q. Zhao, Y. Lyu, J. Wei, S. Wei, Peptide-laden mesoporous silica nanoparticles with promoted bioactivity and osteo-differentiation ability for bone tissue engineering, Colloids Surf. B Biointerfaces 131 (2015) 73-82. https://doi.org/10.1016/j.colsurfb.2015.04.043.

[27] T.-H. Kim, M. Kim, M. Eltohamy, Y.-R. Yun, J.-H. Jang, H.-W. Kim, Efficacy of mesoporous silica nanoparticles in delivering BMP-2 plasmid DNA for in vitro osteogenic stimulation of mesenchymal stem cells, J. Biomed. Mater. Res. A 101 (6) (2013) 1651-1660. https://doi.org/10.1002/jbm.a.34466.

[28] X. Zhou, W. Feng, K. Qiu, L. Chen, W. Wang, W. Nie, X. Mo, C. He, BMP-2 Derived Peptide and Dexamethasone Incorporated Mesoporous Silica Nanoparticles for Enhanced Osteogenic Differentiation of Bone Mesenchymal Stem Cells, ACS Appl. Mater. Interfaces 7 (29) (2015) 15777-15789. https://doi.org/10.1021/acsami.5b02636.

[29] S. Ramakrishna, Z.-M. Huang, Biocomposites, in: I. Milne, R.O. Ritchie, B.L. Karihaloo (Eds.), Comprehensive structural integrity, Elsevier/Pergamon, Amsterdam, Boston, 2003, pp. 215296.

[30] R. McBeath, D.M. Pirone, C.M. Nelson, K. Bhadriraju, C.S. Chen, Cell Shape, Cytoskeletal Tension, and RhoA Regulate Stem Cell Lineage Commitment, Developmental Cell 6 (4) (2004) 483-495. https://doi.org/10.1016/S1534-5807(04)00075-9.

[31] F. Farvadi, M.H. Ghahremani, F. Hashemi, M. Reza Hormozi-Nezhad, M. Raoufi, S. Zanganeh, F. Atyabi, R. Dinarvand, M. Mahmoudi, Cell shape affects nanoparticle uptake and toxicity: An overlooked factor at the nanobio interfaces, Journal of Colloid and Interface Science 531 (2018) 245-252. https://doi.org/10.1016/j.jcis.2018.07.013.

[32] N. Taebnia, D. Morshedi, M. Doostkam, S. Yaghmaei, F. Aliakbari, G. Singh, A. Arpanaei, The effect of mesoporous silica nanoparticle surface chemistry and concentration on the $\alpha$ synuclein fibrillation, RSC Adv. 5 (75) (2015) 60966-60974. https://doi.org/10.1039/C5RA08405A.

[33] J. Schindelin, I. Arganda-Carreras, E. Frise, V. Kaynig, M. Longair, T. Pietzsch, S. Preibisch, C. Rueden, S. Saalfeld, B. Schmid, J.-Y. Tinevez, D.J. White, V. Hartenstein, K. Eliceiri, P. Tomancak, A. Cardona, Fiji: an open-source platform for biological-image analysis, Nature Methods 9 (2012) 676 EP -. https://doi.org/10.1038/nmeth.2019.

[34] F. Lu, S.-H. Wu, Y. Hung, C.-Y. Mou, Size effect on cell uptake in well-suspended, uniform mesoporous silica nanoparticles, Small 5 (12) (2009) 1408-1413. https://doi.org/10.1002/smll.200900005.

[35] G. Quan, X. Pan, Z. Wang, Q. Wu, G. Li, L. Dian, B. Chen, C. Wu, Lactosaminated mesoporous silica nanoparticles for asialoglycoprotein receptor targeted anticancer drug delivery, J. Nanobiotechnology 13 (2015) 7. https://doi.org/10.1186/s12951-015-0068-6.

[36] C. He, Y. Hu, L. Yin, C. Tang, C. Yin, Effects of particle size and surface charge on cellular uptake and biodistribution of polymeric nanoparticles, Biomaterials 31 (13) (2010) 3657- 
3666. https://doi.org/10.1016/j.biomaterials.2010.01.065.

[37] E. Fröhlich, The role of surface charge in cellular uptake and cytotoxicity of medical nanoparticles, Int. J. Nanomedicine 7 (2012) 5577-5591. https://doi.org/10.2147/IJN.S36111.

[38] F. Zhao, Y. Zhao, Y. Liu, X. Chang, C. Chen, Y. Zhao, Cellular uptake, intracellular trafficking, and cytotoxicity of nanomaterials, Small 7 (10) (2011) 1322-1337. https://doi.org/10.1002/smll.201100001.

[39] P. Eaton, P. Quaresma, C. Soares, C. Neves, M.P. de Almeida, E. Pereira, P. West, A direct comparison of experimental methods to measure dimensions of synthetic nanoparticles, Ultramicroscopy 182 (2017) 179-190. https://doi.org/10.1016/j.ultramic.2017.07.001.

[40] D. Lin-Vien, N.B. Colthup, W.G. Fateley, J.G. Grasselli, The Handbook of infrared and raman characteristic frequencies of organic molecules, Academic Press, Boston, 1991.

[41] M.R. Sazegar, A.A. Jalil, S. Triwahyono, R.R. Mukti, M. Aziz, M. Aziz, H.D. Setiabudi, N. Kamarudin, Protonation of Al-grafted mesostructured silica nanoparticles (MSN): Acidity and catalytic activity for cumene conversion, Chemical Engineering Journal 240 (2014) 352-361. https://doi.org/10.1016/j.cej.2013.12.004.

[42] J.G. Croissant, D. Zhang, S. Alsaiari, J. Lu, L. Deng, F. Tamanoi, A.M. AlMalik, J.I. Zink, N.M. Khashab, Protein-gold clusters-capped mesoporous silica nanoparticles for high drug loading, autonomous gemcitabine/doxorubicin co-delivery, and in-vivo tumor imaging, J. Control. Release 229 (2016) 183-191. https://doi.org/10.1016/j.jconrel.2016.03.030.

[43] J. Lin, H. Zhang, Z. Chen, Y. Zheng, Penetration of lipid membranes by gold nanoparticles: Insights into cellular uptake, cytotoxicity, and their relationship, ACS Nano 4 (9) (2010) 54215429. https://doi.org/10.1021/nn1010792.

[44] A.R. Klemm, D. Young, J.B. Lloyd, Effects of Polyethyleneimine on Endocytosis and Lysosome Stability, Biochem. Pharmacol. 56 (1) (1998) 41-46. https://doi.org/10.1016/s00062952(98)00098-7.

[45] F. Wang, A. Salvati, P. Boya, Lysosome-dependent cell death and deregulated autophagy induced by amine-modified polystyrene nanoparticles, Open Biol. 8 (4) (2018). https://doi.org/10.1098/rsob.170271.

[46] I. Schütz, T. Lopez-Hernandez, Q. Gao, D. Puchkov, S. Jabs, D. Nordmeyer, M. Schmudde, E. Rühl, C.M. Graf, V. Haucke, Lysosomal Dysfunction Caused by Cellular Accumulation of Silica Nanoparticles, J. Biol. Chem. 291 (27) (2016) 14170-14184. https://doi.org/10.1074/jbc.M115.710947.

[47] S.T. Stern, P.P. Adiseshaiah, R.M. Crist, Autophagy and lysosomal dysfunction as emerging mechanisms of nanomaterial toxicity, Part. Fibre Toxicol. 9 (2012) 20. https://doi.org/10.1186/1743-8977-9-20.

[48] S.-H. Kim, J. Roszik, E.A. Grimm, S. Ekmekcioglu, Impact of I-Arginine Metabolism on Immune Response and Anticancer Immunotherapy, Front. Oncol. 8 (2018) 67. https://doi.org/10.3389/fonc.2018.00067.

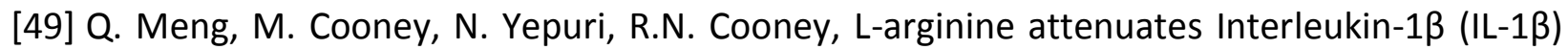


induced Nuclear Factor Kappa-Beta (NF-kB) activation in Caco-2 cells, PLoS ONE 12 (3) (2017) e0174441. https://doi.org/10.1371/journal.pone.0174441.

[50] M. Babaev, A.L. Alyavi, B.A. Alyavi, J.K. Uzokov, P2533Influence of I-arginine aspartate on vascular markers in hypertensive patients with metabolic syndrome, European Heart Journal 39 (suppl_1) (2018). https://doi.org/10.1093/eurheartj/ehy565.P2533.

[51] J. Klawitter, K.L. Hildreth, U. Christians, W.M. Kohrt, K.L. Moreau, A relative L-arginine deficiency contributes to endothelial dysfunction across the stages of the menopausal transition, Physiol. Rep. 5 (17) (2017). https://doi.org/10.14814/phy2.13409.

[52] K.-I. Kamei, Y. Koyama, Y. Tokunaga, Y. Mashimo, M. Yoshioka, C. Fockenberg, R. Mosbergen, O. Korn, C. Wells, Y. Chen, Characterization of Phenotypic and Transcriptional Differences in Human Pluripotent Stem Cells under 2D and 3D Culture Conditions, Adv. Healthc. Mater. 5 (22) (2016) 2951-2958. https://doi.org/10.1002/adhm.201600893.

[53] R.E. Akins, D. Rockwood, K.G. Robinson, D. Sandusky, J. Rabolt, C. Pizarro, Three-dimensional culture alters primary cardiac cell phenotype, Tissue Eng. Part A 16 (2) (2010) 629-641. https://doi.org/10.1089/ten.tea.2009.0458.

[54] M. Post, C. van der Weele, Principles of Tissue Engineering for Food, in: R.P. Lanza, R.S. Langer, J. Vacanti (Eds.), Principles of tissue engineering, Academic Press an imprint of Elsevier, Amsterdam, 2014, pp. 1647-1662.

[55] J.M. Curran, R. Chen, J.A. Hunt, The guidance of human mesenchymal stem cell differentiation in vitro by controlled modifications to the cell substrate, Biomaterials 27 (27) (2006) 4783-4793. https://doi.org/10.1016/j.biomaterials.2006.05.001.

[56] B. Cao, Y. Peng, X. Liu, J. Ding, Effects of Functional Groups of Materials on Nonspecific Adhesion and Chondrogenic Induction of Mesenchymal Stem Cells on Free and Micropatterned Surfaces, ACS Appl. Mater. Interfaces 9 (28) (2017) 23574-23585. https://doi.org/10.1021/acsami.7b08339.

[57] D.S.W. Benoit, M.P. Schwartz, A.R. Durney, K.S. Anseth, Small functional groups for controlled differentiation of hydrogel-encapsulated human mesenchymal stem cells, Nat. Mater. 7 (10) (2008) 816-823. https://doi.org/10.1038/nmat2269. https://doi.org/10.1016/B978-0-12-398358-9.00078-1 